\title{
SATISFAÇÃO PROFISSIONAL DO ENFERMEIRO EDUCADOR: UMA REVISÃO DA LITERATURA
}

\author{
Elaine Maria Ferreira ${ }^{1}$ \\ Maria Romana Friedländer ${ }^{2}$
}

\section{RESUMO}

Através desta revisão de literatura, reunimos conhecimentos existentes acerca da satisfação profissional e identificamos uma ampla diversidade teórica e conceitual, bem como a escassez de estudos que contemplem a satisfação profissional do enfermeiro educador. Esta revisão permitiu a percepção clara da necessidade da realização de pesquisas que identifiquem o estado de satisfação profissional, variáveis envolvidas e suas relações com a influência da trajetória da formação e do estágio de desenvolvimento profissional do enfermeiro professor de Enfermagem.

Palavras-Chave: Enfermagem; Satisfação no Emprego; Docente de Enfermagem.

\section{NURSING EDUCATOR PROFESSIONAL'S SATISFACTION: A REVIEW OF THE LITERATURE}

\section{ABSTRACT}

By means of a review in the literature we gathered the existing knowledge about professional satisfaction and we identified a vast theoretical and conceptual variety as well as lack of studies, which could look at the nurse educator's satisfaction. This review allowed a clear perception of the need to carry out researches, which could identify the professional's satisfaction status, the involved variables and their relationships with the influence of the formation trajectory and the stage of professional development of the nursing professor nurse.

Keywords: Nursing; Job satisfaction; Nursing Professor.

\section{SATISFACCIÓN PROFESIONAL DEL ENFERMERO EDUCADOR: UNA REVISIÓN DE LA LITERATURA}

\section{RESUMEN}

Atraves de la revisión de la literatura, reunimos conocimientos existentes acerca de la satisfacción profesional e identificamos una amplia diversidad teórica y conceptual, bien como la escasez de estudios que contemplen la satisfacción profesional del enfermero educador. Esta revisión permitió la percepción clara de la necesidad de la realización de pesquisas que identifiquen el estado de satisfacción profesional, variables envueltas y sus relaciones con la influencia de la trayectoria de la formación y de prácticas de desarrollo profesional del enfermero profesor de Enfermería.

Palabras clave: Enfermería; Satisfacción en el Empleo; Docente en Enfermería.

\footnotetext{
${ }^{1}$ Enfermeira do Hospital São Paulo. Pós-graduação em Gerenciamento de Serviços de Enfermagem pela UNIFESP. E-mail: elainemogi@yahoo.com.br

${ }^{2}$ Doutora e Livre Docente pela USP. Ex-Professora Titular e Atual Membro do Núcleo de Gerenciamento de Serviços de Saúde e de Enfermagem da UNIFESP. Coordenadora de Pesquisa em Enfermagem da Universidade Católica Portuguesa (Lisboa). Email: mrfriedlander@yahoo.com.br
} 


\section{INTRODUÇÃOO}

$A$ importância de estudos que contemplem a satisfação profissional parece ser evidente quando considerada sua influência sobre o comportamento profissional e social do indivíduo, uma vez que o trabalho passa a ser observado sob uma concepção mais ampla e a satisfação laboral passa a ser parte integrante da satisfação na vida.

$O$ interesse pela satisfação profissional do enfermeiro educador nasce da concepção de que o ensino formal é o meio utilizado para a formação dos profissionais e que serão futuramente os responsáveis pelo desenvolvimento técnico-científico da Enfermagem, assumindo as inúmeras responsabilidades do competitivo mercado de trabalho. Os cursos de graduação, sendo o contexto de formação/estruturação da personalidade profissional do enfermeiro, aparecem como uma das principais fontes geradoras de transformações na profissão.

Nesse contexto, a satisfação do professor pode influenciar de maneira direta ou indireta, positiva ou negativa, o desenvolvimento do ensino, sua qualidade e a percepção dos alunos em relação à profissão. Um profissional/professor insatisfeito ou pouco motivado pode gerar um significativo desequilíbrio no desenvolvimento de suas atividades, desempenhando suas funções de forma inadequada e influenciando negativamente os membros envolvidos no processo de ensino-aprendizagem. De maneira semelhante, um professor motivado por seu trabalho poderá influenciar de forma positiva as pessoas com quem trabalha e as tarefas poderão ser desempenhadas de forma harmoniosa e produtiva.

Considerando essa relação, propomos-nos a realizar uma revisão da literatura a fim de reunir conhecimentos existentes, destacar as lacunas percebidas e proporcionar subsídios para a realização de estudos que contemplem a Satisfação Profissional do Enfermeiro Educador. Vale ressaltar que este estudo não tem a pretensão de ser exaustivo, nem tampouco esgotar a investigação sobre o tema.

\section{1) Satisfação Profissional}

\section{1 - Precursores históricos}

A satisfação do indivíduo no trabalho começou a ser estudada por volta de 1912, nas pesquisas de Taylor sobre "Gerência Científica". Estas concebem a influência do ambiente de trabalho sobre o desempenho dos indivíduos, salientando a atuação da fadiga e do salário sobre a satisfação e a produtividade do trabalhador.
Por volta de 1930, estudos realizados por Elton Mayo e colaboradores passam a considerar que a maneira de o homem pensar e avaliar seu trabalho influencia suas reações frente ao mesmo. Além disso, concluíram que a natureza do trabalho, a adaptabilidade do empregado à situação, a identificação do grupo sócioeconômico e as relações sociais exercem muito mais influência sobre a satisfação profissional do que a recompensa salarial.

$\mathrm{Na}$ mesma década, Hoppock ${ }^{(1)}$ publicou o primeiro estudo intensivo sobre o tema, evidenciando outros fatores que influenciam a satisfação, entre eles a monotonia, supervisão, condições de trabalho e desempenho $^{(1,2)}$.

Além dos estudos de Taylor e Mayo, que geraram respectivamente a Teoria Científica e a Teoria das Relações Humanas, outros também contemplam e são muito utilizados como referencial para os estudos sobre 0 tema, além de terem contribuído significativamente para a humanização dos ambientes de trabalho(3).

Entre elas, a Teoria das Necessidades Humanas Básicas, elaborada por Abraham $\mathrm{H}$. Maslow $^{(4)}$ em 1943. Essa considera que o indivíduo busca seus objetivos e o atendimento de suas necessidades de acordo com o valor que atribui a mesma, ou seja, através da motivação. Assim, as necessidades humanas puderam ser classificadas em cinco níveis - necessidades fisiológicas básicas, necessidades de auto-estima, auto-realização, segurança e sociais.

Baseados nesses princípios, Herzberg, Mausner e Snyderman ${ }^{(5)}$ desenvolveram a Teoria dos Dois Fatores em 1959. Essa considera a satisfação e a insatisfação como fenômenos separados e nem sempre relacionados. Assim, os fatores que influenciam a satisfação profissional do indivíduo podem ser considerados como:

- Fatores intrínsecos ao trabalho ou fatores motivadores (realização, responsabilidade e reconhecimento): exercem influência direta na satisfação, podendo gerála. Correspondem às necessidades de alto nível, relacionadas ao desempenho individual do trabalhador e ao relacionamento que este estabelece consigo mesmo.

- Fatores extrínsecos ao trabalho ou fatores higiênicos (administração e política organizacional, supervisão, salário e condições de trabalho): são necessidades de nível mais baixo que não promovem a satisfação, mas evitam a insatisfação.

No Brasil, Martins ${ }^{(6)}$ realizou um dos primeiros trabalhos sobre o tema. A autora busca esclarecer a relação entre diversos fatores e a satisfação profissional. Através de levantamento bibliográfico evidencia que os 
estudos da satisfação profissional enquadramse em três escolas que, de acordo com os precursores históricos adotados, combinam conceitos e procuram especificar quais as variáveis relevantes e de que forma essas se relacionam para determinar a satisfação. Essas escolas são:

- Escola físico-econômica: estuda a satisfação em relação a funções de condições físicas/ambientais e do correspondente pagamento relacionados ao trabalho;

- Escola social: relaciona a satisfação às relações sociais estabelecidas no ambiente de trabalho, tais como a qualidade da supervisão, da integração do grupo de trabalho e das boas relações;

- Escola do próprio trabalho: considera a satisfação como uma decorrência do aumento de habilidades, eficácia e responsabilidade advindas do próprio trabalho.

A autora ressalta que são muitas as teorias produzidas e utilizadas para nortear a busca de conhecimentos sobre o tema, não havendo uma universalmente aceita. Essa diversidade gera dúvidas sobre quais os aspectos que devem ser abordados ao se estudar a satisfação profissional, dificultando o entendimento e a concordância em relação à forma como eles se comportam na determinação da mesma.

Estudos das últimas décadas também apontam essa problemática, visto diversos trabalhos abordarem o tema, mas poucos contemplarem com maior profundidade as relações entre as diversas variáveis envolvidas $^{(7,8)}$.

Neste levantamento bibliográfico também verificamos que, a partir da década de 1980, muitos estudos foram realizados no Brasil, entretanto abordando a satisfação profissional como um fator implícito a outras temáticas, tais como qualidade de vida, qualidade dos serviços prestados, produtividade da indústria, satisfação do cliente e sentimentos do profissional.

\section{2 - Definição}

Diante de fundamentação teórica tão diversificada, e acompanhando as mudanças contextuais ocorridas, a conceituação da satisfação profissional também passa por processo evolutivo para definições mais elaboradas.

Wanous e Lawler $^{(9)}$, tentando classificar as várias tendências identificadas nos conceitos de satisfação, tomaram diferentes definições encontradas na literatura e as transformaram em nove modelos gerais. Dentre esses modelos, os autores enfatizam a existência de definições para a satisfação geral com o trabalho e para a satisfação com aspectos particulares do trabalho. Além disso, consideram as relações entre valores, necessidades e expectativas dos sujeitos no entendimento de sua satisfação profissional.

Quadro 1 - Modelos gerais de definição de satisfação profissional propostos por Wanous e Lawler $^{(9)}$

\begin{tabular}{|c|}
\hline \\
\hline $\begin{array}{l}\left.\text { [ST = } \sum(\mathrm{I} \times \mathrm{AST})\right] \\
\text { total no trabalho (ST) } \\
\text { la importância (I) que os } \\
\text { ho têm para o indivíduo } \\
\text { nciam a satisfação no trab }\end{array}$ \\
\hline $\begin{array}{l}\text { Modelo 3: ST = soma de } \mathrm{Nr} \\
\text { Satisfação no trabalho (ST) é a soma } \\
\text { necessidades realizadas (Nr) do sujeito nos } \\
\text { aspectos do trabalho. }\end{array}$ \\
\hline $\begin{array}{l}{\left[\mathrm{ST}=\sum(\mathrm{I} \times \mathrm{Nr})\right]} \\
\text { no trabalho (ST) é a soma do produ }\end{array}$ \\
\hline $\begin{array}{l}{\left[\mathrm{ST}=\sum(\mathrm{E}-0)\right]} \\
\text { no trabalho } \quad(\mathrm{ST}) \text { é a soma }\end{array}$ \\
\hline
\end{tabular}

Modelo 6: [ST $=\Sigma(\mathrm{I}) \times(\mathrm{E}-\mathrm{O})]$

Satisfação no trabalho (ST) é a soma do produto da importância (I) dos vários aspectos do trabalho entre o que o sujeito espera obter $(E)$ e o que ele obtém (0) em cada aspecto.

Modelo 7: [ST = $\Sigma(D-O)]$

Satisfação (ST) é a soma da discrepância entre os desejos (D) do indivíduo e suas realizações ou o que ele obtém ( 0$)$, nos vários aspectos do trabalho.

Modelo 8: [ST $=\Sigma(\mathrm{I}) \times(\mathrm{D}-\mathrm{O})]$

Satisfação (ST) é a soma do produto da importância (I) que o sujeito atribui aos vários aspectos do trabalho pela discrepância entre seus desejos (D) e suas realizações (O).

Modelo 9: [ST = $\Sigma(\mathrm{I}-\mathrm{O})$ ]

Satisfação no trabalho (ST) é a soma da diferença entre a importância (I) atribuída pelo sujeito aos vários aspectos do trabalho e o que ele obtém (0) em cada um deles.

Fonte: Elaborado pelos autores com base em Martins (1985).

Segundo Locke ${ }^{(10)}$, esses modelos se propõem a fornecer uma melhor compreensão do fenômeno; advém de conceitos baseados em diferentes fundamentações teóricas, podendo ser classificados como Modelos Causais ou Teorias de Processo, quando procuram especificar os tipos de variáveis consideradas relevantes e de que forma essas se combinam para determinar a satisfação, ou Teorias de Conteúdo que tentam identificar necessidades ou valores específicos que mais contribuem para a satisfação. 
Poucos autores utilizam a explicação da satisfação como um conceito integrado, devido à dificuldade de reunir em uma mesma definição os muitos e variados aspectos relacionados ao tema.

Locke $^{(10)}$, estudando as causas da satisfação profissional e tentando sistematizar essa integração, relacionou o conceito de satisfação profissional a conteúdos e processos mentais, moral e envolvimento no trabalho. Assim, concebe a satisfação profissional como "um estado emocional agradável ou positivo resultante da avaliação de algum trabalho ou de experiências no trabalho"(2,11).

Através desse conceito, verificamos que a satisfação profissional envolve um processo mental de avaliação das experiências no trabalho, este influenciado ou mediado por vários conteúdos mentais (conhecimentos, crenças, valores, experiências), que não necessariamente estejam relacionados somente ao trabalho. Em outras palavras: o homem avalia suas experiências no trabalho utilizando a bagagem individual de crenças e valores que traz consigo, gerando um estado emocional, que, se agradável, produz satisfação; se desagradável, leva à insatisfação.

Martins $^{(6)}$ atenta para o fato de esta ser uma definição geral e vaga, que exige melhores esclarecimentos de termos envolvidos, para minimizar limitações, visto existirem várias formas de se conceber estado emocional agradável, bem como processos e conteúdos mentais.

Apesar disso, esse conceito é utilizado como referencial em grande parte dos estudos nacionais realizados sobre o tema, por vezes acrescidas de outras considerações, como o fez Lino" ${ }^{(7)}$ "trata-se de um fenômeno complexo e multifatorial relacionado ao indivíduo enquanto ser humano - seu bem estar físico e emocional, sua qualidade de vida - e ao indivíduo enquanto trabalhador qualidade do trabalho, desempenho, produtividade, pontualidade".

\section{3 - Componentes da satisfação} profissional: algumas considerações

Segundo linguagem da pesquisa quantitativa, a satisfação profissional pode ser considerada variável independente quando se relaciona a outras variáveis, sem explicitar as relações; ou variável dependente - quando é abordada como consequiência de outra variável.

Entre os diversos estudos relacionados à satisfação profissional, são encontrados muitos fatores emergentes desse tema, estes abordados de forma igualmente diversa, o que torna difícil a identificação de conceitos e concepções predominantes.
Blegen $^{(12)}$, realizou uma análise aprofundada desses estudos e identificou trinta variáveis relacionadas ao tema. Entretanto, ao analisar os dados, concluiu que diversas denominações eram atribuídas a um mesmo correspondente, o que possibilitou a redução das mesmas ao número de treze e posterior classificação em variáveis de atributo pessoal (também denominados traços de personalidade ou fatores sóciodemográficos, incluem idade, educação, tempo de experiência e locus do controle) e variáveis de atributo profissional (ou aspectos organizacionais: autonomia, compromisso, comunicação com os colegas e com a chefia, eqüidade, profissionalismo, reconhecimento, rotinização e estresse).

Algumas das relações estabelecidas entre essas variáveis e a satisfação profissional, segundo a autora, são as seguintes:

- Idade e tempo de experiência: quanto maior a idade e o tempo de experiência, maior a tendência à estabilidade dentro de um grupo de trabalho e de demonstrar satisfação profissional.

- Estado conjugal: apesar do conflito entre as obrigações profissionais e familiares, não há clareza sobre uma relação determinante entre esse fator e a satisfação.

- Educação/nível de formação: inferese que quanto mais alto o nível de formação profissional, maior é a importância no trabalho realizado. Dessa forma, é evidenciada uma relação inversamente proporcional entre a importância do trabalho e a satisfação.

- Autonomia: entendida como a responsabilidade individual pelo trabalho ou pelas decisões profissionais, associa-se às variáveis de centralização do poder de decisão, participação na tomada de decisão, liberdade e controle pessoal. Destas, a centralização e a impotência mantêm relação inversa com a autonomia.

- Compromisso ou comprometimento: refere-se à lealdade e à alienação, mantendo a última uma relação inversa com a variável chave.

- Comunicação com o colega: nesse contexto, está relacionada à coesão de grupo e integração social. Considerando a comunicação com a chefia, está relacionada ao apoio do líder e ao grau em que o líder deixa claro e define seu papel e o que espera dos profissionais.

- Equidade: relaciona-se à justiça, políticas justas de recompensas e punições.

- Profissionalismo: possui dimensões na motivação e compromisso com a carreira.

- Reconhecimento: relaciona-se de forma cíclica com o resultado do trabalho - o 
estado de satisfação influi positivamente no resultado do trabalho gerando satisfação.

- Rotinização: refere-se à realização de tarefas repetitivas e/ou sob rotinas préestabelecidas. Esse contexto de atividades está geralmente associado à geração de estados de descontentamento em relação ao trabalho, guardando relação inversamente proporcional à satisfação.

\section{4 - Formas de avaliar a Satisfação Profissional}

Ao lidarmos com a avaliação da satisfação profissional, devemos nos atentar ao conceito e/ou teoria que fundamenta a elaboração do instrumento ou escolha da estratégia utilizada, bem como quais os critérios utilizados para validação do mesmo. Diante das diversas bases conceituais e teóricas utilizadas nos estudos sobre o tema, não podemos considerar que os vários instrumentos de medida existentes avaliam o mesmo aspecto, visto que as dimensões do conceito abordado em cada um deles podem não coincidir.

Essa problemática tem impossibilitado a obtenção de relações estáveis e correspondentes entre a satisfação profissional e os fatores envolvidos. Podemos então inferir que é mais seguro a comparação de dados entre pesquisas quantitativas que tenham utilizado o mesmo instrumento e que, quando utilizados diferentes instrumentos, mesmo buscando relações entre as mesmas variáveis, devemos atribuir especial atenção ao generalizá-los, já que as medidas utilizadas podem não estar avaliando a mesma coisa ${ }^{(6)}$. Vale esclarecer que na pesquisa qualitativa os resultados não são generalizáveis, pois expressam o fenômeno em momento e realidade específicos, objetivando o entendimento do mesmo sob ótica determinada.

Através de revisão bibliográfica pudemos observar que grande parte dos estudos sobre - tema adota a metodologia quantitativa, sendo que os instrumentos mais utilizados para mensuração da satisfação profissional são compostos pelas escalas tipo Likert ou Thurstone, escalas de face e listas de adjetivos, que requerem respostas "sim", "não" ou "em dúvida".

A metodologia qualitativa passa a ser adotada com maior freqüência diante da necessidade de esclarecimentos sobre 0 comportamento e a relação entre os diversos fatores influenciadores no estado de satisfação e/ou insatisfação do trabalhador, sendo a entrevista um dos métodos mais comumente descritos.

As manifestações comportamentais do indivíduo em ambiente de trabalho também são utilizadas, apesar de alguns pesquisadores considerarem este método bastante inadequado por não se conhecer com clareza a influência da satisfação profissional sobre o comportamento humano $^{(2,13)}$.

Segundo Del Cura e Rodrigues ${ }^{(13)}$, também são utilizadas escalas de tendência de ação, nas quais se solicita ao indivíduo que relate tendências de ações que ele experimentou com relação ao seu trabalho. Entretanto, ressaltam que as perguntas abertas podem gerar respostas não estruturadas e subjetivas, dificultando a sua comparação.

$\mathrm{Na}$ realidade, não há um consenso sobre qual o instrumento e/ou estratégia mais adequados e em quais ambientes utilizá-los. 0 que ocorre é que este e os fatores a serem medidos e/ou estudados são influenciados pela base teórica que fundamenta a investigação. Sendo assim, consideramos que o instrumento mais apropriado é aquele que mede exatamente o que se objetiva medir, e a estratégia é aquela que permite um adequado entendimento do fenômeno.

\section{Satisfação Profissional do Professor/Edu- cador}

As investigações sobre satisfação profissional do professor são ainda relativamente escassas e recentes, sendo que muitos dos estudos existentes aparecem associados a outras temáticas, como motivação, qualidade de vida, identidade dos professores, stress e desafios profissionais ou mal-estar docente. Além disso, por vezes, utilizam conceitos, teorias e avaliações adaptadas de outras áreas, sem considerar as características próprias do contexto de ensino, seu sistema de valores, conteúdo e forma de trabalho.

Os primeiros estudos encontrados acerca da satisfação profissional do professor são do início da década de 1970. Nota-se que a partir dos anos oitenta, o interesse foi direcionado às relações existentes entre a satisfação profissional e a qualidade de vida, a saúde mental e o meio familiar ${ }^{(14)}$, muito provavelmente em virtude do início do processo de democratização do ensino, que levou a um aumento significativo da população escolar, acompanhado pelo surgimento de alguns indicadores e manifestações de mal-estar e insatisfação dos docentes $^{(15,16)}$.

Através de levantamento bibliográfico, fica evidente a existência de número significativo de estudos relativos à insatisfação profissional do professor (por vezes expressos como dilemas, desafios, sofrimento, conflitos), sendo estes substancialmente numerosos quando comparados aos que focam a vertente da satisfação $^{(17)}$. 
Também percebemos que, mesmo frente às escassas publicações referentes ao tema, grande parte delas são de origem portuguesa, demonstrando o interesse dessa nação pelo contexto educacional. Também convém ressaltar que essas abordam principalmente aspectos relacionados ao professor atuante no ensino fundamental $e$ médio.

De modo geral, chama a atenção a gradual e significante redução da satisfação profissional entre os professores. Estudos realizados por Fuller e Miskel (in CordeiroAlves, 1991) na década de 1970, nos EUA, revelaram que aproximadamente $90 \%$ dos professores sentiam-se satisfeitos com sua profissão. No início da década de oitenta, houve um acentuado decréscimo percentual, com pouco mais de $75 \%$ dos professores a afirmarem a sua satisfação (Bebtzen e Heckman in Cordeiro-Alves, 1991). Já na década de 90, num estudo desenvolvido com professores ingleses, Chaplain ${ }^{(18)}$ constatou que apenas $37 \%$ da amostra estava satisfeito com o ensino enquanto profissão.

Dentre as diversas variáveis que produzem efeitos na satisfação profissional do professor, uma das mais comumente estudadas é a etapa ou o momento vivenciado pelo profissional em sua carreira.

Encontramos muitos estudos sobre esse aspecto, contendo diferentes concepções relacionadas às bases teóricas utilizadas. Baseados em agrupamento feito por Moreira ${ }^{(19)}$, apresentaremos de forma relativamente simplificada algumas dessas bases reunidas em três grupos:

1. O primeiro deles concebe a linha cognitivo-desenvolvimentista, derivada do modelo piagetiano. Considera $o$ desenvolvimento profissional dos professores na acepção de desenvolvimento cognitivo: o professor atravessa estágios cognitivos cada vez mais sofisticados, sendo seu pensamento caracterizado em cada estágio por uma estrutura de conjunto subjacente, que se torna cada vez mais complexa, abstrata e abrangente.

o quadro a seguir traz exemplos de características atribuídas ao pensamento do professor em três dos níveis propostos por Sprinthall e Thies-Sprinthall (1980) e David Hunt (1971), estudiosos dessa perspectiva.
Quadro 2 - Características do pensamento do professor em diferentes estágios de desenvolvimento cognitivo - modelo proposto por Sprinthall (1980).

\begin{tabular}{|l|l|}
\hline ESTAGIO A & $\begin{array}{l}\text { - Vê o conhecimento como fixo } \\
\text { - Concebe o ensino como "encher os } \\
\text { alunos de matéria” } \\
\text { - Não questiona autoridade e não } \\
\text { espera que os alunos o façam } \\
\text { - Segue rigorosamente o método de } \\
\text { ensino que lhe é indicado } \\
\text { - Prefere receber instruções claras e } \\
\text { concretas. }\end{array}$ \\
\hline ESTAGIO B & $\begin{array}{l}\text { - Preocupa-se um pouco com a } \\
\text { aplicação e generalização dos } \\
\text { conhecimentos por parte dos alunos } \\
\text { - Demonstra alguma autonomia em } \\
\text { sua aprendizagem e espera o mesmo } \\
\text { de seus alunos } \\
\text { - Está aberto a inovações e tenta } \\
\text { adaptar-se pessoalmente aos } \\
\text { métodos de ensino. }\end{array}$ \\
\hline ESTAGIO C & $\begin{array}{l}\text { - Reconhece a rápida transformação } \\
\text { e evolução dos conhecimentos; } \\
\text { - Ensina os alunos a investigar e a } \\
\text { pensar criticamente sobre os } \\
\text { conteúdos e suas implicações } \\
\text { - Não segue automaticamente as } \\
\text { indicações de autoridade, } \\
\text { questionando as suas razões } \\
\text { - Encoraja os alunos a uma postura } \\
\text { questionadora } \\
\text { - É capaz de utilizar uma grande } \\
\text { variedade de métodos de ensino, e } \\
\text { de adaptá-los às características dos } \\
\text { alunos. }\end{array}$ \\
\hline
\end{tabular}

Fonte: Adaptado de Moreira ${ }^{(19}$

2. Num segundo tipo, o desenvolvimento dos professores refere-se à aquisição progressiva de competências. Essa considera que 0 conhecimento profissional dos professores é adquirido progressivamente através do contato com o ambiente e contexto de trabalho (Doyle, 1986; Jackson, 1968). Assim, através do acompanhamento e comparação sistemática de professores no decorrer de sua carreira foi possível identificar e caracterizar a progressiva aquisição de competências e verificar suas implicações na prática docente (Adams, 1982).

Também fazem parte desse grupo os estudos que acompanharam a evolução das preocupações ou dos problemas sentidos pelos professores, segundo 0 estágio de desenvolvimento/amadurecimento vivenciado. Neste modelo, são citados estudos de Frances Fuller (1969), Feiman-Nemser e Floden (1986), Tomás (1987), Bejarano (2001).

O modelo de Fuller (1969) foi desenvolvido a partir de uma série de encontros periódicos de discussão livre, com um grupo de professores estagiários em seu primeiro ano de prática. A autora verificou que ao longo do 
tempo ocorreram mudanças progressivas nos tópicos de discussão e propôs, então, um esquema geral de evolução das preocupações dos professores, com três categorias.

Quadro 3 - Preocupações típicas do professor, em cada estágio, segundo modelo de Fuller.

\begin{tabular}{|c|c|c|c|}
\hline ESTÁGIO & Sobrevivência & Eficácia & Impacto \\
\hline $\begin{array}{l}\text { PREOCUPAÇŌES } \\
\text { DOMINANTES }\end{array}$ & Ele mesmo & Tarefa & Alunos \\
\hline $\begin{array}{l}\text { PREOCUPAÇÕES } \\
\text { TÍPICAS }\end{array}$ & $\begin{array}{l}\text { - Será que sou } \\
\text { capaz? } \\
\text { - Onde estou } \\
\text { situado? } \\
\text { - Quão } \\
\text { adequado eu } \\
\text { estou? } \\
-\quad \text { que os } \\
\text { alunos pensam } \\
\text { de mim? } \\
-\quad 0 \text { que os } \\
\text { colegas } \\
\text { pensam de } \\
\text { mim? } \\
\text { - O que vou } \\
\text { fazer diante de } \\
\text { uma situação } \\
\text { inesperada? }\end{array}$ & $\begin{array}{l}\text { - Qual a } \\
\text { melhor } \\
\text { maneira } \\
\text { ensinar a } \\
\text { matéria? } \\
\text { - Como } \\
\text { dominar } \\
\text { a sala de } \\
\text { aula? } \\
-\quad 0 \text { que } \\
\text { faço } \\
\text { para que } \\
\text { os alunos } \\
\text { prestem } \\
\text { atenção? }\end{array}$ & $\begin{array}{l}\text { - Os alunos } \\
\text { estão } \\
\text { aprendendo? } \\
\text { - O que posso } \\
\text { fazer para } \\
\text { influenciar } \\
\text { esse ganho? }\end{array}$ \\
\hline
\end{tabular}

A este modelo de desenvolvimento proposto por Fuller em 1969, a partir de novo estudo realizado por Fuller e Bown em 1975, foi adicionada uma categoria (ou estágio). 0 quadro seguinte sintetiza as características de cada um dos estágios ${ }^{(20)}$.

Quadro 4 - Modelo de desenvolvimento do professor (Fuller e Bown, 1975).

\begin{tabular}{|c|c|}
\hline Estágios & Preocupações dos professores \\
\hline $\begin{array}{l}\text { Primeiro } \\
\text { estágio: } \\
\text { Pré-ensino }\end{array}$ & $\begin{array}{l}\text { Os futuros professores tendem a se } \\
\text { identificar realisticamente mais } \\
\text { como alunos do que como } \\
\text { professores. Suas preocupações não } \\
\text { passam de vagas apreensões. }\end{array}$ \\
\hline $\begin{array}{c}\text { Segundo } \\
\text { estágio: } \\
\text { Novato no início } \\
\text { do ensino e/ou } \\
\text { ainda dentro do } \\
\text { programa de } \\
\text { pré-serviço }\end{array}$ & $\begin{array}{l}\text { Início de contatos sistemáticos com o } \\
\text { ensino, seja no estágio supervisionado } \\
\text { ou no início da profissão. Professores } \\
\text { desenvolvem preocupações com a } \\
\text { sobrevivência em sala de aula e no } \\
\text { ambiente escolar. Novatos tendem } \\
\text { essa busca pela sobrevivência como } \\
\text { controle de classe, domínio de } \\
\text { conteúdo. Sua própria adequação é } \\
\text { determinada pelo desempenho de seu } \\
\text { papel como professor. }\end{array}$ \\
\hline $\begin{array}{c}\text { Terceiro } \\
\text { estágio: } \\
\text { Novato a partir } \\
\text { de seu primeiro } \\
\text { ano de ensino } \\
\end{array}$ & $\begin{array}{l}\text { Suas preocupações se focam no } \\
\text { ensino, especificamente em sua } \\
\text { performance, limitações } \\
\text { frustrações das situações de ensino. }\end{array}$ \\
\hline $\begin{array}{l}\text { Quarto estágio: } \\
\text { Professor } \\
\text { experiente }\end{array}$ & $\begin{array}{l}\text { As preocupações do professor } \\
\text { experiente se voltam para os alunos } \\
\text { (suas necessidades sociais, } \\
\text { acadêmicas e emocionais). O } \\
\text { professor desenvolve habilidade para } \\
\text { entender os alunos como indivíduos. }\end{array}$ \\
\hline
\end{tabular}

Fuller considera o princípio da psicologia da motivação para explicar o mecanismo responsável pelo avanço dos professores ao longo dos estágios: as necessidades de nível superior não se manifestam antes que as mais básicas estejam satisfeitas. Assim, a mudança de estágios ocorre em função da progressiva resolução das dificuldades ou carências sentidas em determinado nível, resultando na aquisição de competências pelo professor.

3. 0 terceiro tipo considera o desenvolvimento do professor ao longo de seu ciclo de vida profissional. Dentro desse modelo, destaca-se 0 proposto por $M$. Huberman $(1989,1992)$.

Considerando que todo professor vivencia ciclos ou fases de adaptação à sua função profissional, referentes ao momento vivenciado em sua carreira, e com base em autobiografias orais, Huberman analisou os percursos profissionais seguidos pelos sujeitos, elaborou um modelo geral desse percurso e propôs hipóteses causais acerca de acontecimentos que facilitam ou dificultam a ocorrência de situações positivas ou negativas nesse contexto.

As diversas fases ou ciclos vivenciados pelo professor em sua carreira foram denominadas pelo autor como: entrada na carreira, fase de estabilização, fase de diversificação, fase de "pôr-se em questão", serenidade e distanciamento afetivo, conservação e lamentações e "desinvestimento", ou seja, deixa de investir em seu aprimoramento.

Utilizando-se dessas bases teóricas, um número significativo de estudos conclui a existência de correlações entre as diversas fases de desenvolvimento do professor e sua satisfação profissional. Segundo Pedro e Peixoto $^{(17)}$, autores como Kyriacou e Sutcliffe (1979), Lopes (2001) e Gonçalves (1992) evidenciaram uma elevação dos níveis de satisfação profissional junto aos professores mais velhos e mais experientes. Já Gursel, Sunbul e Sari (2002) e Scoot, Cox e Dinham (1999) a satisfação profissional progride de forma inversa aos anos de carreira, sendo que os professores mais velhos demonstram menor satisfação no trabalho. Não obstante, encontramos as investigações de Teodoro (1994), Cordeiro-Alves (1994) e Chaplain (1995) que constataram que os professores em meados da carreira apresentam maiores sintomas de desmotivação e tensões profissionais. Portanto, os resultados apresentam-se extremamente divergentes de estudo para estudo, impossibilitando a aquisição de conclusões seguras. 
2.1 - Ser professor/educador: algumas considerações

0 ensino formal é um processo interativo, interpessoal e intencional, que utiliza a comunicação verbal, o discurso dialógico orientado e a demonstração como meios de provocar, favorecer e levar ao êxito a aprendizagem em determinadas situações ${ }^{(21)}$. 0 professor é agente ativo nesse processo, sendo um indivíduo que exerce ações sobre outro (o aluno), com finalidade de introduzilo na arte e na ciência de algum conhecimento ou profissão e o capacitar para o exercício desta ${ }^{(22)}$. Ensinar é uma atividade complexa, e os fatores que envolvem o ensino são também complexos e múltiplos ${ }^{(23)}$.

Não podemos deixar de conceber que, em contexto mais amplo, a prática de ensino sofre influências e influencia os processos sociais de desenvolvimento econômico, científico e tecnológico. Nas últimas décadas temos vivenciado constantes transformações decorrentes da globalização, do avanço tecnológico e do acesso aparentemente universal à informação, entre elas a geração de um mercado de trabalho altamente competitivo, repleto de novas exigências.

Não obstante, as universidades passam por uma fase de adaptação e agregação de novos conceitos, diante das atribuições decorrentes de sua inserção na dinâmica da sociedade. Essa realidade traz implicações, dentre elas a de que alunos e organização de ensino esperam e solicitam do professor a capacidade de interar essas transformações sociais ao processo educacional e, conseqüentemente, formar indivíduos que atendam as exigências do mercado de trabalho. Além disso, os professores lidam com a ampliação de suas funções tradicionais, com as exigências de maiores esforços no planejamento e elaboração de propostas docentes, aumento da burocratização didática, entre outros ${ }^{(24-25)}$.

Nessas perspectivas, inferimos que 0 professor atua de forma fundamental na integração entre diversos aspectos (sejam estes características individuais, expectativas e/ou necessidades) oriundos do aluno, do professor e da instituição de ensino envolvida.

Professor e aluno buscam o atendimento de seus objetivos individuais; são dotados de amadurecimento, necessidades, expectativas, experiências, formação, valores e fatores culturais distintos, estes influindo diretamente em sua vida, em seu comportamento, seu desempenho profissional e no relacionamento que estabelecem consigo próprio (autoconceito) e com os outros (relações sociais).

0 aluno, requerendo o desenvolvimento de habilidades necessárias a sua futura atuação profissional, busca estabelecer integrações que the permitam agir como sujeito ativo no processo ensino-aprendizagem, expressar seu potencial, reconhecer e trabalhar suas dificuldades, buscar e desenvolver conhecimentos. Para isso espera a atribuição de atividades que o estimulem e orientem a pesquisar, ler, experimentar, elaborar, questionar sistematicamente, criar alternativas e desenvolver autonomia reflexiva e habilidades.

$\mathrm{Na}$ instituição de ensino, o processo de trabalho do professor lida com filosofias, metas e objetivos organizacionais próprios. Em geral, se empenham em formar alunos qualificados, com bases excelentes, raciocínio confiável e sólidos conhecimentos, que se adaptem com facilidade ao mercado de trabalho e se desenvolvam profissionalmente. Dessa forma, já que esses alunos levam consigo o referencial da instituição formadora, cria-se um marketing institucional que serve de auxílio para a manutenção da instituição no mercado altamente competitivo. Vale lembrar que, para a concretização desse processo, a instituição precisa de um corpo docente de boa qualidade, com vontade de ensinar, com capacidade de manter e ampliar seus conhecimentos e de transmiti-los de maneira satisfatória.

Em se tratando do professor, consideramos primariamente que todos os que ensinam o fazem por gostar de fazê-lo. É um agente fundamental no processo ensinoaprendizagem, que além de buscar a satisfação de suas próprias necessidades de desenvolvimento, reconhecimento e realização pessoal e profissional, age como intermediário na relação do aluno com a instituição de ensino (o que o aluno busca e o que a instituição oferece). Para isso necessita desenvolver competências, além da habilidade de ensinar, refletir, adaptar informações de acordo com as reações dos alunos e a evolução da situação pedagógica e do contexto, solucionar problemas variados, relatar, mobilizar e justificar os conhecimentos, e articular a teoria à prática.

Ser professor é ser agente ativo de transformações; é promover mudanças na forma de sentir, pensar e agir das pessoas em relação a si mesmas e aos outros; é estar atento ao seu próprio processo de desenvolvimento; é lidar com a gestão de conflitos educacionais; é buscar equilíbrio entre a satisfação das necessidades do aluno, da instituição e as suas próprias; é levar os alunos a aprender a aprender, a ser, a fazer, a conviver e a conhecer.

\section{2) Satisfação Profissional na Enfermagem}

Ao buscarmos na literatura conhecimentos referentes à satisfação profissional na 
Enfermagem, encontramos a citação de um primeiro trabalho realizado na década de 1950 por Robert P. Bullock ${ }^{(7)}$. Nas décadas posteriores, inúmeros foram os estudos internacionais publicados, a grande maioria referindo-se a satisfação profissional no contexto assistencial da profissão.

A partir da década de oitenta surgem numerosas publicações nacionais abordando o tema, muitas vezes como um fator implícito a outras temáticas (qualidade de vida, qualidade dos serviços, produtividade, satisfação de clientes, sofrimento no trabalho, entre outras).

Muitos instrumentos para mensuração da satisfação profissional foram desenvolvidos, visando o conhecimento e a avaliação das dimensões individuais, sociais e organizacionais do trabalho da Enfermagem. Porém a fundamentação teórica inconsistente e pouco clara quanto à especificação das variáveis dificultaram um real entendimento do assunto.

De forma semelhante, diversos estudos também utilizam instrumentos desenvolvidos por pesquisadores de outras áreas profissionais, principalmente da Psicologia Ocupacional e Social.

Ao realizarmos levantamento bibliográfico, não encontramos nenhuma publicação que contemple a satisfação profissional do professor de Enfermagem. Por sua vez, vale informar sobre um artigo encaminhado para a Revista Texto-contexto Enfermagem, pelos autores Ferreira EM, Schippers PFG, Tanaka LH, Friedländer MR. Satisfação profissional do enfermeiro professor de enfermagem: um estudo qualitativo, enviado em Fev./2007. A grande maioria contempla a área assistencial, entre elas alguns estudos aqui referenciados ${ }^{(2-}$ $3,6-8,11,13,26)$. Na área de ensino, os diversos estudos existentes abordam temáticas igualmente diversas, tendo como objetos de estudo o aluno, as práticas pedagógicas, 0 contexto e desenvolvimento do processo ensino-aprendizagem, entre outros.

\section{CONSIDERAÇÕES FINAIS}

Esta revisão da literatura evidencia a existência de diversos trabalhos que contemplam a satisfação profissional, entretanto utilizando-se de fundamentação teórica muito diversificada, o que dificulta um real entendimento do tema, bem como a concordância em relação à forma como as diversas variáveis relacionadas se comportam ao influenciar a satisfação.

Em decorrência, o constructo satisfação profissional recebe conceitos igualmente diversos, o que amplia as formas de concebê-la e dificulta a interpretação, a generalização e comparação dos resultados das pesquisas realizadas.

Em se tratando especificamente da satisfação profissional do professor, os estudos são relativamente escassos e recentes. Estes, predominantemente, estão associados a outras temáticas, contemplam o professor atuante no ensino fundamental e médio e/ou utilizam conceitos, teorias e avaliações adaptadas de outras áreas, sem considerar as características próprias do contexto de ensino, seu sistema de valores, conteúdo e forma de trabalho.

Alguns desses apontam uma diminuição progressiva da satisfação profissional do professor, bem como a existência de correlações entre as diversas fases de desenvolvimento desse profissional e sua satisfação, entretanto os resultados são controversos.

Não foram encontradas publicações que contemplem a satisfação profissional do professor de Enfermagem.

Evidenciamos, portanto, tratar-se de um tema amplo e complexo, havendo a necessidade de realização de pesquisas que identifiquem o estado de satisfação do enfermeiro educador, bem como estudos que contemplem as variáveis envolvidas, a influência da trajetória da formação e do estágio de desenvolvimento desse profissional em sua satisfação laboral. Sugerimos a formação de grupos de pesquisa que adote a satisfação profissional do enfermeiro educador como objeto de estudo.

\section{REFERÊNCIAS}

1. Hoppock R. Job satisfaction. New York, Harper \& Row Publishers; 1930.

2. Del Cura MLA. Satisfação profissional do enfermeiro. [dissertação] Ribeirão Preto (SP): Escola de Enfermagem da USP; 1994.

3. Matsuda LM. Satisfação profissional da equipe de enfermagem de uma UTI-adulto: perspectiva de gestão para a qualidade da assistência. [doutorado] Ribeirão Preto (SP): Escola da Enfermagem da USP; 2002.

4. Maslow AH. A theory of human motivation. Psychological Review; 1943.

5. Herzberg F, Mausner B, Snyderman B. The motivation to work. New York: Willy; 1959.

6. Martins MCF. Satisfação no trabalho: elaboração de um instrumento e variáveis que afetam a satisfação. [dissertação] Brasília (GO): Universidade de Brasília; 1985.

7. Lino MM. Satisfação profissional entre enfermeiras de UTI: adaptação transcultural do index of work satisfaction (IWS). [dissertação] São Paulo (SP): Escola de Enfermagem da USP; 1999. 
8. Santos MS dos. A (in) satisfação do enfermeiro no trabalho: implicações para o gerenciamento das ações de enfermagem - aspectos teóricos. [dissertação] Ribeirão Preto: Escola de Enfermagem da USP; 1999.

9. Wanous JP, Lawler IIIEE. Measurement and meaning of job satisfaction. Journal of applied Psychology 1972; 56 (2):95-105.

10. Locke EA. The nature and causes of job satisfaction. In: Dunnete MD, editors. Handbook of industrial and organizational psychology. Chicago: Rand MacNally College Publishing Co; 1976.

11. Antunes AV; Sant Anna LR. Satisfação e motivação no trabalho do enfermeiro. Rev Bras Enferm. 1996; 49(3): 425-434.

12. Blegen MA. Nurses' job satisfaction: a metaanalysis of related variables. Nurs Res 1993; 42(1): 36-41.

13. Del Cura MLA, Rodrigues ARF. Satisfação profissional do enfermeiro. Rev. Latino-am Enfermagem 1999; 7(4): 21-8.

14. Seco GB. A satisfação na actividade docente. Coimbra (Portugal): Universidade de Coimbra; 2000.

15. Cordeiro-Alves F. Estudo da satisfação/insatisfação dos professores efectivos do $3^{\circ}$ ciclo do ensino básico e do ensino secundário do distrito de Bragança. [dissertação] Lisboa (Portugal): Faculdade de Psicologia e Ciências da Educação da Universidade de Lisboa; 1991.

16. Barros J, Neto F. Solidão nos professores. Rev. Portuguesa de Pedagogia 1992; 26:1-17.

17. Pedro N, Peixoto F. Satisfação Profissional e auto-estima em professores dos $2^{\circ}$ e $3^{\circ}$ ciclos do ensino básico. Análise Psicológica 2006; 2(24): 247 262.
18. Chaplain RP. Stress and job satisfaction: a study of english primary school teachers. Educational Psycology 1995; 15:473-489.

19. Moreira JM. Desenvolvimento profissional dos professores: acepções, concepções e implicações. III Seminário de Psicologia na formação de professores e outros agentes educativos. Évora; 1991.

20. Camargo S, Nardi R. Formação de professores de física: os estágios supervisionados como fonte de pesquisa sobre a prática de ensino. Revista da Abrapec 2003; [online]. [citado $2007 \mathrm{fev}$. 22]. Disponível

em: http://www4.fc.unesp.br/abrapec/revistas/v3n3a 3.pdf.Ano2003

21. Paquay L, Perrenoud $P$, Altet $M$, Charlier E. Formando professores profissionais. $2^{\mathrm{a}}$ ed. Porto Alegre: ArtMed; 2001.

22. Friedlander MR, Moreira MTA. Formação do enfermeiro: características do professor e do sucesso escolar. Rev. Bras. Enf. 2006; 59(1):9-13.

23. Bejarano NRR. Tornando-se professor de física: conflitos e preocupações na formação inicial. [doutorado] São Paulo: Faculdade de Educação da USP; 2001.

24. Santos LHP dos, Cassiani SH de B. Vivendo em constante conflito: o significado da prática docente no ensino médio de enfermagem. Rev.latino-am. Enfermagem 2000; 8(5):58-64.

25. Sodré SMS. Dilemas dos licenciados em ciências biológicas quando da inserção no contexto da prática. [mestrado] Salvador (BA): Universidade Federal da Bahia; 2005.

26. Ferreira EF, Possari JF, Moderno AMB. Fatores de satisfação e insatisfação profissional do enfermeiro de centro cirúrgico de um hospital universitário de grande porte. Revista SOBECC 2006; 11(2):15-23. 